\title{
Research on the Relationship Between Online Learning Behavior and Learning Effect of College Students in the Digital Learning Environment
}

\author{
Xiaolei $\mathrm{Lu}^{1}$, Jing Qiu, ${ }^{2, *}$, Ruiwu $\mathrm{Wu}^{2, *}$ \\ ${ }^{1}$ School of Engineering, Yunnan University of Business Management, Kunming 650106, Yunnan, China \\ ${ }^{2}$ Teaching Affairs Department, Yunnan Agricultural University, Kunming 650201, Yunnan, China \\ ${ }^{3}$ School of Big Data (School of Information Engineering), Yunnan Agricultural University, Kunming 650201, Yunnan, \\ China \\ ${ }^{*}$ Corresponding author. Email: 2008004@ynau.edu.cn \\ *Corresponding author. Email: wrw107@sina.com
}

\begin{abstract}
This study determined 7 indicators that affect the learning effect of online learning behaviors by consulting relevant literature materials, and used SPSS21.0 to analyse and research the learning behavior data of college students. The study found that the length of the online learning time interval has a significant impact on the online learning effect of college students. The learning effect of students in the short-time interval group is significantly higher than that of the students in the long-time interval group. Different time interval groups have a certain effect on students' final exam results. Test efficiency, test completion rate, and test timeliness have significant effects on college students' learning effects, while the number of forums initiated, the number of replies, and the average test attempt rate have little effect on learning effects. The results show that: decentralized learning is conducive to improving the online learning effect of college students; the online teaching platform should be more intelligent and have automatic reminder function; teaching resources should be based on knowledge points and suitable for fragmented learning; teachers should pay more attention to the learning process of students' management, strengthen the supervision of teaching links; students should strengthen the training of knowledge points. This research provides an effective path for how to improve the teaching level of teachers and the learning effect of students under the new teaching mode.
\end{abstract}

Keywords: digital learning environment, online learning behavior, learning effect

\section{INTRODUCTION}

In 2012, the "Ten-Year Development Plan for Education Informatization (2011-2020)" issued by the Ministry of Education pointed out that "providing a personalized, lifelong learning informatization environment and service for each learner" [1]. In the field of education, with the advancement of education informatization, education big data has become a national strategy in my country, and the construction of education big data has ushered in a major historical opportunity for development. Education is considered to be the industry most relevant to big data after the Internet and e-commerce. A large amount of data has been accumulated in education big data. How to use these data to conduct big data analysis and prediction, dig out valuable information from the massive data, and apply its conclusions to the process of teaching and learning, has great the practical significance of [2]. Through in-depth mining of multi-dimensional education big data, it is possible to accurately and effectively research and analyse student behavior data, help teachers to have a deeper understanding of student knowledge and learning preferences, and help promote traditional "teacher-centered" The transformation of teaching methods to "student-centered" teaching methods [3].

Students' learning behavior is an important part of teaching, many researchers have conducted analysis and research on it, and have achieved certain research results. Abroad has been rich in the study of student learning behavior, especially in the research of imposing different interventions on students to improve student 
learning behavior. This has also played an important role in promoting the development of foreign curriculum teaching. At present, there are few domestic researches on learning behavior. Liu Xunxing uses association rules to mine effective online distance education learning behavior patterns, which is of great significance for improving the management level and learning evaluation mode [4]. Through the questionnaires of users and the structural equation method, Du Zhitao analysed the main factors that affect the online micro-learning behavior. The learning situation has the most critical impact on the microlearning behavior [5]. Li $\mathrm{Sa}$ uses an association rule mining algorithm to analyse the relationship between learners' learning behaviors and learning effects. The experimental results show that there are significant differences between individual students in most of the learning behaviors in classroom experiments, and there are five types of students. There is a significant positive correlation between learning behavior participation frequency and learning effect [6]. Shen Xinyi [7] researchers used various research methods such as Delphi method, expert ranking method, expert workshop, etc., to construct MOOCAP online learning behavior and learning evaluation model.

According to the research results of the above researchers, it is found that there are many factors influencing the effect of learners' online learning. How to dig out the factors that affect learners' learning from education big data is of great significance to improve learners' learning effects. This research intends to use college students' online learning data as the research object to explore the relationship between college students' online learning behaviors and learning effects.

\section{RESEARCH DESIGN}

\subsection{Research sample}

The research object of this research is the undergraduate students who participated in the online learning of the "Linear Algebra" course in a university in the 2019-2020 academic year. There are 387 students in total, including 217 boys and 170 girls. The students' academic backgrounds include economic management, water conservancy and hydropower, and architecture. Class and other majors.

\subsection{Research process}

The teaching method of this course adopts a mixed teaching mode. Teaching resources are released on the network teaching platform, and relevant teaching content is pushed to each student before the class. It is required to do a good preparation and record the problems encountered in the learning process; The teacher first checks the mastery of the students through training, and asks the students to raise the problems encountered in the learning process, focusing on the difficulties and key points of the knowledge; after class tests the students' classroom learning situation, and pushes 10 exercises to the students for the test; each chapter explains After the end, perform a chapter test. The system sets that each exercise and chapter test of a student can be repeatedly submitted. The system automatically records the number of exercises and chapter tests and average scores of each student. The submission time of each exercise and test is allowed to be delayed; respectively in the 8th week and a mid-term and final exam will be held in the 16th teaching week.

\subsection{Data collection and analysis}

The study collected a total of 24381 online learning data of the research object on the online teaching platform, and analysed the data, and obtained 23176 valid data. Learning effect test indicators: three indicators: test average score, mid-term exam score, and final exam score; learning behavior indicators: online learning time interval, number of forums initiated, number of replies, test effectiveness, test completion rate, test timeliness and average test attempt rate. The relationship between learning behavior indicators and learning effect is tested by $\mathrm{T}$ test and correlation coefficient analysis methods. The data indicators collected in the study are shown in Table 1. This study stipulates: learning effect $=$ average test score $* 20 \%+$ mid-term exam score $* 10 \%+$ final exam score $* 70 \%$.

Table 1. Description of data indicators collected by the study

\begin{tabular}{|c|l|l|}
\hline $\begin{array}{c}\text { Evaluation } \\
\text { indicator }\end{array}$ & \multicolumn{1}{|c|}{ indicator } & \multicolumn{1}{c|}{ Description } \\
\hline \multirow{2}{*}{$\begin{array}{c}\text { learning } \\
\text { effect }\end{array}$} & average test score & $\begin{array}{l}\text { The total score of the exercises and chapter tests divided by the total } \\
\text { number of tests (the question type is multiple-choice questions, the total } \\
\text { score of each exercise and test is } 100 \text { points, each test time is } 1 \text { hour, each } \\
\text { time can be submitted multiple times) }\end{array}$ \\
\cline { 2 - 3 } & mid-term exam score & $\begin{array}{l}\text { Comprehensive examination (including multiple-choice questions, fill-in- } \\
\text { the-blank questions and calculation questions, the total score is } 100 \text { points, } \\
\text { the examination time is } 2 \text { hours, and can only be submitted once) }\end{array}$ \\
\hline
\end{tabular}




\begin{tabular}{|c|c|c|}
\hline & final exam score & $\begin{array}{l}\text { Comprehensive examination (including multiple-choice questions, fill-in- } \\
\text { the-blank questions and calculation questions, the total score is } 100 \text { points, } \\
\text { the examination time is } 2 \text { hours, and can only be submitted once) }\end{array}$ \\
\hline \multirow{7}{*}{$\begin{array}{l}\text { learning } \\
\text { behavior }\end{array}$} & $\begin{array}{l}\text { online learning time interval } \\
\text { (day) }\end{array}$ & Average time between login to the platform \\
\hline & number of forums initiated & Number of forums posted about learning \\
\hline & number of replies & Reply to the number of forums initiated \\
\hline & test effectiveness $(\%)$ & Average test accuracy / average test completion time \\
\hline & test completion rate $(\%)$ & number of completed tests / total number of times \\
\hline & test timeliness $(\%)$ & number of tests completed on time / total number of tests \\
\hline & $\begin{array}{l}\text { average test attempt rate }(\% \\
\text { ) }\end{array}$ & $\begin{array}{l}\text { (Total number of tests-total number of tests-number of unfinished tests) / } \\
\text { total number of tests }\end{array}$ \\
\hline
\end{tabular}

\section{DATA ANALYSIS AND RESEARCH RESULTS}

This research uses SPSS 21.0 to analyse online learning data to find out the relationship between college students' online learning behavior and learning effect.

\subsection{Research on the impact of students' learning behaviors on learning effects at different online learning time intervals}

Statistics of online learning data show that the average sample interval is 6.38 days, the longest interval is 14 days, the shortest interval is 1 day, and the median is 6 days. In order to better study the influence of the length of the online learning time interval on the learning effect. This study divides the sample into two groups: the short interval group (interval time is $0-6$ days, not including 6 days); the long interval group (interval time is 6-14 days). The analysis results are shown in Table 2.

Table 2. Comparative analysis table of learning effect and learning behavior indicators of students in different time interval groups

\begin{tabular}{|c|c|c|c|c|c|}
\hline \multirow{2}{*}{\begin{tabular}{c}
\multirow{2}{*}{ indicator } \\
\cline { 2 - 5 }
\end{tabular}} & \multicolumn{2}{|c|}{ short-time interval group $(\mathrm{N}=119)$} & \multicolumn{2}{l}{ long-time interval group (N=118 } & \multirow{2}{*}{ Sig. } \\
\cline { 2 - 5 } & Mean & Standard deviation & Mean & Standard deviation & \\
\hline learning effect & 82.08 & 7.87 & 65.91 & 9.70 & 0.001 \\
\hline mid-term exam score & 83.77 & 10.46 & 63.07 & 11.22 & 0.002 \\
\hline average test score & 87.70 & 5.24 & 77.56 & 9.93 & 0 \\
\hline final exam score & 89.94 & 10.38 & 70.64 & 11.73 & 0.001 \\
\hline number of forums initiated & 0.43 & 0.605 & 0.50 & 0.884 & 0.468 \\
\hline number of replies & 0.53 & 0.790 & 0.46 & 0.579 & 0.526 \\
\hline test effectiveness (\%) & 86.24 & 10.76 & 66.03 & 11.62 & 0.002 \\
\hline test completion rate (\%) & 93.63 & 12.079 & 71.66 & 16.802 & 0.001 \\
\hline test timeliness (\%) & 86.67 & 11.89 & 65.16 & 12.29 & 0 \\
\hline average test attempt rate (\%) & 0.64 & 0.63 & 0.69 & 0.784 & 0.606 \\
\hline
\end{tabular}

It can be seen from Table 2 that from the three indicators of learning effect, the scores of the mid-term exam, the average test score and the final exam scores of the short-time interval group are higher than the scores of the long-time interval group, indicating that the learning effect of students in the short time interval group is longer The learning effect of the students in the time interval group is good; the sig values of the learning effect, test efficiency, test completion rate and test timeliness of the different time interval groups are all less than 0.05 , indicating that the length of the online learning time interval affects the learning effect, test efficiency, and test of college students Completion rate and test timeliness have a significant impact; students in different time interval groups have little effect on the number of forums initiated, the number of replies and the average test attempt rate of college students. 


\subsection{Research on the influence of different time interval groups on learning effect}

In order to better explore the impact of different time interval groups on the learning effect, the covariance analysis is used to analyse the impact of mid-term exam results on final exam results. The mid-term test scores are used as covariates, and different time interval groups are used as fixed factors to perform covariance analysis.

The $\mathrm{F}$ value of the midterm exam score is 589.398 , and the sig. value is $0.000<0.05$, indicating that there is a linear relationship between the midterm exam score and the final exam score; the $\mathrm{F}$ value of the different time interval group is 9.943 , sig. $0.002<0.05$, indicating that different time interval groups have a significant impact on the final exam results.

\subsection{Correlation analysis of learning effects and learning behavior indicators}

The correlation analysis between the learning effect of the students in the sample and the 7 learning behavior indicators is carried out, and the analysis results are shown in Table 3.

Table 3. Correlation analysis table of learning effect and learning behavior indicators

\begin{tabular}{|c|c|c|c|c|c|c|c|}
\hline $\begin{array}{l}\text { Correlation } \\
\text { coefficient }\end{array}$ & $\begin{array}{l}\text { online learning time } \\
\text { interval }\end{array}$ & $\begin{array}{c}\text { number of } \\
\text { forums initiated }\end{array}$ & $\begin{array}{c}\text { number of } \\
\text { replies }\end{array}$ & $\begin{array}{c}\text { test } \\
\text { effectiveness }\end{array}$ & $\begin{array}{c}\text { test } \\
\text { completion } \\
\text { rate }\end{array}$ & $\begin{array}{c}\text { test } \\
\text { timeliness }\end{array}$ & $\begin{array}{l}\text { average test } \\
\text { attempt rate }\end{array}$ \\
\hline learning effect & $-0.793^{* *}$ & 0.045 & $0.621^{* *}$ & $0.933^{* *}$ & $0.931^{* *}$ & $0.937^{\text {*** }}$ & $0.154^{*}$ \\
\hline
\end{tabular}

**. Significantly correlated at 0.01 level (two-sided).*. Significantly correlated at 0.01 level (two-sided).

It can be seen from Table 3 that there is a significant negative correlation between the online learning effect of college students and the online learning time interval correlation coefficient, indicating that the shorter the online learning interval, the higher the learning effect; it is related to the test efficiency, test completion rate, test timeliness and number of replies. Significantly positive correlation, indicating that the accuracy of the test, completing homework on time, and actively answering questions, the better the learning effect; significant positive correlation with the average number of attempts of the test at the 0.05 level, indicating that the more the average test attempt rate, the longer it takes Conducive to improving the effect of learning.

\subsection{Comparative analysis of learning effect and learning behavior}

Divide the five learning behavior indicators of test effectiveness, test completion rate, test timeliness, and test average trial rate into different groups, find sample statistical characteristics according to different groups, and analyze whether different groups have a significant impact on learning effects. The analysis results are shown in Table 4.

Table 4. Comparison and analysis table of learning effect and learning behavior indicators

\begin{tabular}{|c|c|c|c|c|c|}
\hline \multirow{2}{*}{ Learning behavior } & \multirow{2}{*}{ Grouping } & \multirow{2}{*}{$\begin{array}{l}\text { Number of } \\
\text { samples }\end{array}$} & \multicolumn{2}{|c|}{ learning effect } & \multirow{2}{*}{ Sig. } \\
\hline & & & Standard deviation & Mean & \\
\hline \multirow{2}{*}{$\begin{array}{l}\text { online learning time } \\
\text { interval }\end{array}$} & shornot-time & 119 & 82.08 & 7.87 & \multirow[t]{2}{*}{0.001} \\
\hline & long-time & 118 & 65.91 & 9.70 & \\
\hline \multirow{2}{*}{$\begin{array}{c}\text { number of forums } \\
\text { initiated }\end{array}$} & $>0$ & 148 & 73.93 & 12.67 & \multirow{2}{*}{0.862} \\
\hline & $=0$ & 89 & 74.19 & 10.78 & \\
\hline \multirow{2}{*}{ number of replies } & $>0$ & 145 & 73.77 & 12.46 & \multirow[b]{2}{*}{0.677} \\
\hline & $=0$ & 92 & 74.44 & 10.66 & \\
\hline \multirow{3}{*}{ test effectiveness (\%) } & $>80 \%$ & 104 & 85.51 & 3.69 & \multirow{3}{*}{0.012} \\
\hline & $60 \%-80 \%$ & 104 & 67.32 & 6.83 & \\
\hline & $<60 \%$ & 29 & 56.87 & 4.86 & \\
\hline \multirow{2}{*}{$\begin{array}{c}\text { test completion rate }(\% \\
\text { ) }\end{array}$} & 100 & 122 & 82.65 & 8.95 & \multirow[b]{2}{*}{0.008} \\
\hline & $<100$ & 115 & 64.89 & 6.92 & \\
\hline \multirow{2}{*}{ test timeliness $(\%)$} & $>80 \%$ & 104 & 85.52 & 3.68 & \multirow{2}{*}{0.001} \\
\hline & $60 \%-80 \%$ & 99 & 67.86 & 6.46 & \\
\hline
\end{tabular}




\begin{tabular}{cccccc} 
& $<60 \%$ & 34 & 56.83 & 4.87 & \\
\hline & $>0$ & 150 & 77.52 & 8.37 & \\
$\begin{array}{c}\text { average test attempt rate } \\
(\%)\end{array}$ & $=0$ & 56 & 73.86 & 14.85 & 0.016 \\
& $<0$ & 31 & 57.42 & 5.46 & \\
\hline
\end{tabular}

It can be seen from Table 4 that the higher the test efficiency, test completion rate, test timeliness and average attempt rate, the better the learning effect of students; the learning effect of students who have completed the test is significantly higher than that of students who have not completed the test. From the perspective of significance level, the significance level of test time interval, test completion rate, test timeliness, test efficiency, and test average trial rate is less than 0.05 , indicating the learning effect and test time interval, test completion rate, test timeliness, test The five learning behavior indicators of performance and test average attempt rate are all significantly correlated. It shows that after many trainings, students can improve their learning effects. The learning effect is not significantly related to the number of forums initiated, the number of replies, and the test performance indicators.

\section{CONCLUSIONS AND RECOMMENDATIONS}

\subsection{Conclusion}

This research analyses and researches the online learning behavior and learning effect data of college students in the "Linear Algebra" course on the network teaching platform, and the following conclusions are obtained.

First, the analysis of the impact of students' learning behaviors on learning results at different online learning time intervals.

According to the results of data analysis, the learning effect of short-term students is significantly better than that of long-term students. The length of the time interval has a significant impact on the learning effect, test efficiency, test completion rate and test timeliness, but has little effect on the number of forums initiated, the number of replies and the average test attempt rate. The experimental results show that multiple repetitions and intensive training are conducive to mastering knowledge points, improving the accuracy and timeliness of testing, and improving the learning effect of students.

Second, analysis of the impact of different time interval groups on students' learning effects.

According to the results of covariance analysis, it is shown that there is a linear relationship between mid- term test scores and final test scores; groups of different time intervals have a significant impact on students' final test scores.

Third, the correlation analysis between learning effect and learning behavior indicators.

According to the experimental analysis results, the shorter the learning time interval, the better the online learning effect of college students. This also effectively confirms that the learning effect of the students in the short time interval group is significantly better than the learning effect of the students in the long time interval group; It is helpful to improve the test efficiency, completion rate and timeliness of college students; the more college students reply on the platform, the more they motivate college students to think positively, which is conducive to improving the learning effect of college students; repeating exercises and testing multiple times will promote the learning effect of college students to a certain extent effect.

Fourth, comparative analysis of learning effects and learning behavior indicators.

According to the results of data analysis, the higher the test performance, test completion rate, test timeliness and average trial rate, the better the student's learning effect; test time interval, test completion rate, test timeliness, test effectiveness and average test trial rate are 5 The indicators significantly affect the learning effect of students.

Research has found that although some students have low test performance in the first test, they have improved the accuracy of the test and reduced the time to test the test after repeated training, thereby improving the test efficiency and learning effect. The test efficiency index is to test the proficiency and accuracy of students in doing the questions. The value of the test efficiency index is to find the average score of the students in multiple tests. Therefore, there are students with low test efficiency, which may not necessarily lead to poor learning effects.

\subsection{Recommendation}

First, from the research conclusions, college students' test performance, test completion rate, test effectiveness, and average test attempt rate all have a certain impact on the learning effect of college students. This shows that the teacher should pay attention to the implementation of homework assignments when designing teaching activities. Troubleshooting, 
supervision, feedback and other links. For each knowledge point mentioned, the students' learning situation will be tested by assigning homework, and each student will be urged to submit the homework according to the submission situation of the student's homework. Students master every knowledge point.

Second, the number of replies from college students has a significant positive correlation with the learning effect. Class teachers should change the way of teaching, from "teacher-centered" to "student-centered". Classes can be discussed on a certain topic to stimulate students' active thinking and cultivate independent learning ability and lifelong learning ability.

Third, the time interval for college students to log on to the online teaching platform significantly affects the learning effect of college students. Therefore, the presentation of teaching resources of the online teaching platform, the amount of homework, and how to design the teaching all need to be considered. Online teaching resources should be based on knowledge points and record 10-15 minutes of teaching videos. When a certain knowledge point is finished in class, the corresponding homework should be assigned. The number of questions should not be too many. About 10 questions are appropriate to test whether students have mastered the relevant knowledge points. If college students do not log in to the platform for a certain period of time or the homework test is not completed, the platform should be able to push relevant information to college students, remind them to $\log$ in to the platform and complete related tasks.

Fourth, for college students' repeated training is conducive to improving the learning effect, the resources of the online teaching platform should have playback functions, and the assignments and unit tests assigned by the teacher should be set to be able to repeat the assignments at the specified time to strengthen students' knowledge grasp.

\section{ACKNOWLEDGMENTS}

This research was supported by the Research Project of Undergraduate Education and Teaching Reform in Yunnan Province in 2018 "Research on Modern Agricultural Talent Cultivation Model of Local Agriculture and Forestry Colleges Serving Rural Revitalization Strategy"(Project Number: JG2018087) and Student Science Research Fund Project of Yunnan University of Business Management in 2020 "Research on the Status and Ability Improvement of College Students' Autonomous Learning under the Background of 'Internet + Education' " (Project Number: 2020XK11)

\section{REFERENCES}

[1] Ministry of Education. (2012). Ten-year development plan for education informatization ( 2011-2020

.http://www.moe.gov.cn/srcsite/A16/s3342/201203 /t20120313_133322.html.

[2] Zhao Jianwei, Peng Chengyuan. (2019).An empirical study of college students' online learning behavior under the background of education big data. Contemporary Education Research and Teaching Practice (15), 34-35. doi:10.16534/j.cnki.cn13-9000/g.2019.1676.

[3] LI Dan, SUN Jin-ping, KANG Xiao-feng.(2019). Multidimensional Learning Behavior Analysis System Based on Big Data Cloud Platform. Computer Knowledge and Technology (29),47-49. doi:10.14004/j.cnki.ckt.2019.3420.

[4] LIU Xun-xing.(2017). Analyzing the Learning Behavioral Effect of the Network Distance Education. Computer Knowledge and Technology (11),118-120. doi:10.14004/j.cnki.ckt.2017.1228.

[5] Du Zhitao.(2017). Factors Influencing the Behavior of Network "Micro-learning "Participants: Empirical Analysis Based on Structural Equation Model. Journal of Intelligence (01), 173-181+200. doi: 10.3969/j.iss.1002-1965.2017.01.030

[6] Li Sa.(2018). Study on correlation analysis Method of Learning Behavior Based on Association Rules. Microelectronics \& Computer (06),65-68. doi:10.19304/j.cnki.issn1000-7180.2018.06.014.

[7] Xinyi Shen, Jianwei Wu, Yanxia Zhang, Ying Li and Yuchun Ma.(2019). Towards an evaluation model of online learning behavior and learning effectiveness for MOOCAP learners. Distance Education in China (07),38-46+93. doi:10.13541/j.cnki.chinade.20190508.002. 